\title{
Response of a circular steel plate with different weld geometries subject to impact loading
}

\author{
S. Abdel-Malek, L.W. Meyer, and N. Herzig \\ Nordmetall Impact Dynamics GmbH, Hauptstrasse 16, 09221 Adorf, Germany, www.nordmetall.net
}

\begin{abstract}
The dynamic response of clamped circular steel plates was experimentally investigated under impact loading. The experiments were performed using a high energy drop weight machine with a 5 ton drop weight, which falls from a height of $0.8 \mathrm{~m}$ and results in a total impact energy of $40 \mathrm{~kJ}$. Target plates of $10 \mathrm{~mm}$ thickness and $580 \mathrm{~mm}$ diameter were welded in three different geometrical configurations of weld elements on the lower side. The impact process was carried out using a hemispherical punch. The force was registered by strain gages on the punch. A full dynamic strain field measurement was applied on the tension side using two high speed cameras. The evaluation of the strain field was carried out with the speckle photography technique. The effect of cracks and welding on the deformation and failure behavior was studied using pre-cracked disks and plates with welded webs, welded circular discs and also with a weld seam only. The failure of the plates was registered using the high speed cameras and from the force signal. The results are analyzed and discussed regarding the behavior of the material and component under high rate loading.
\end{abstract}

\section{Introduction}

Under ballistic loadings, materials used in armor applications are exposed to different kinds of high rate stresses. According to different capabilities of withstanding loading conditions, materials will react with distinct, materialspecific strengths and failures. In this context, it is necessary to know these characteristics in order to use each material in the appropriate application. Until now only monoaxial material behavior of a virgin material was used to explain the behavior of complex structures under blast loading and/or under high dynamic impact loading.

Protection of metallic structures against impact loading is of relevance to the present threat sceneries in safety applications. Due to the complex nature of the problem, the structural behavior under impact and blast loading is still not fully understood, despite a large number of studies have been carried out in the last few decades [1-5]. Most of these studies are either computational analysis with FE-methods or experimental investigations with explosive mediums, by which one can only appraise the end results. In this study the armor plates were impacted with a large hemispherical punch to simulate the blast loading. During the test the force and the strain field on the opposite side of the specimen are measured.

Armor structures consist not only of plain plates. They contain also connection elements such as welding, bolts and rivets, which are considered as weak points. The most cracks, which cause catastrophic failure, are originated at welding joints. Neglecting these weak points and investigating only the virgin armor plates itself would be inexpedient. From this point of view, cracked plates and plates with a different welding configurations are studied in this investigation in addition to smooth plates.

Understanding the dynamic behavior of blast loaded armor steel plates is a key knowledge for successful protection projects. The materials of armor plates are tested at high strain rates, and constitutive models are developed to describe the behavior under impact loading. Failure models are also developed to characterize the different failure modes [6,7]. Simulations of the impacted plates are carried out using a FEM explicit code. Using the developed constitutive material, the FE-computations can be calibrated. A comparison of the measured and calculated forces can also be carried out.

\section{Experimental work}

To investigate the behavior of the materials used in armor applications to withstand a certain blast load, a special test method, developed by Nordmetall GmbH is used [1]. Under blast loading a two dimensional tension/tension stress state occurs in the plate or in the vehicle. This biaxial stress state affects the behavior of materials significantly and is therefore not comparable to the uni-axial (conventional) tensile test. To assess the behavior of sheet metal structures, mainly of welded structures or of notched parts under explosive conditions by mine blasts or IED's, the company Nordmetall $\mathrm{GmbH}$ has developed a new test method.

This blast equivalent, biaxial tension-tension stress can be realized with the help of a Nordmetall-bulge device at lower velocities than a normal blast consists, but with the advantage to record forces, displacements and strain fields up to fracture, which cannot be determined in a mine explosion test. This bulge device is an open cylinder positioned in the drop weight machine and is headed with the test plate, which is impacted by a semi-spherical punch. The cylinder has two windows for the application of two high speed optical cameras. Hence, it is possible to observe the lower side of the loaded plates and to measure the local deformation of the plate by stochastic patterns during the high rate bulge test.

\subsection{Fatigue pre-cracking}

The specimens for testing the influence of a fatigue precrack were notched on a milling machine. A V-shaped 


\section{$\varnothing 580$}

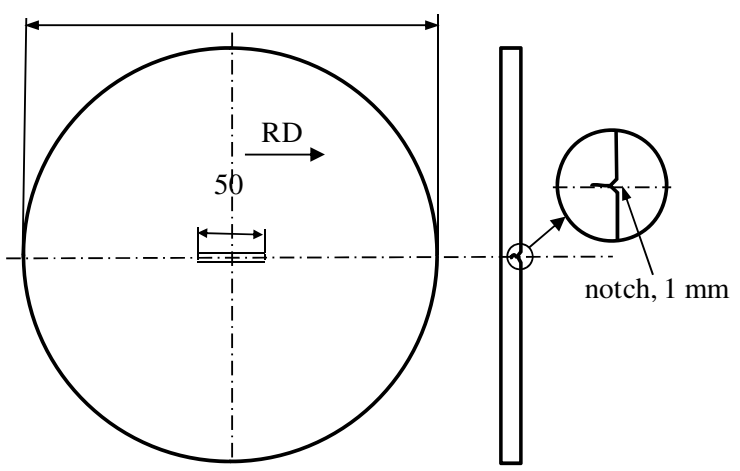

Fig. 1. Specimen and notch geometry for testing with a fatigue pre-crack.

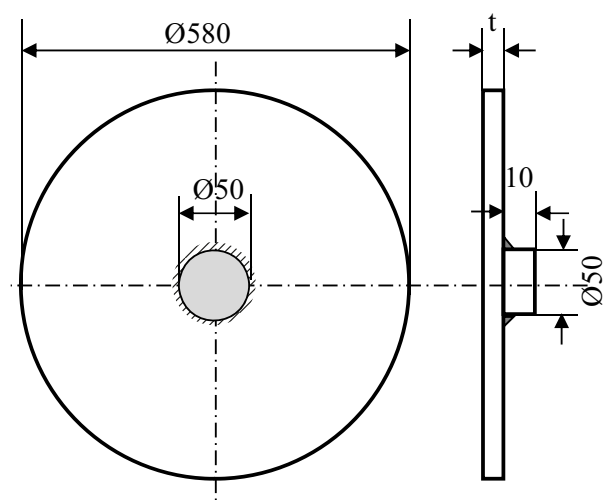

Fig. 2. Specimen with welded disc.

notch with a depth of $1 \mathrm{~mm}$ and a length of $50 \mathrm{~mm}$ was milled along the rolling direction in the middle of the testing disc. Fatigue pre-cracking was carried out using an electro mechanical resonant testing machine, figure 1 . The testing disc was applied on two round end supports and loaded using a round end punch with a frequency of $60 \mathrm{~Hz}$.

\subsection{Welding}

To investigate the influence of the weld configuration on the behavior of structures under impact loading, pieces of different geometries from the identical test material were welded into the middle of the specimen according to DIN EN 12534. Three forms of the weld pieces are selected: discs $\varnothing 50 \mathrm{~mm}$ as in figure 2 , rings $\varnothing_{\mathrm{o}} / \varnothing_{i}=50 / 40 \mathrm{~mm}$ and webs $10 \times 50 \mathrm{~mm}$. The used welding method is "metal inert gas" = MIG.

\subsection{Test setup}

To simulate a blast loading on armor plates, a new test procedure with a dynamic biaxial tension-tension stress state was developed at Nordmetall GmbH using the NordmetallJUMBO-drop weight machine. The JUMBO-drop weight machine is a Nordmetall designed apparatus. It consists of a heavy anvil, a frame, and a drop weight with a mass of

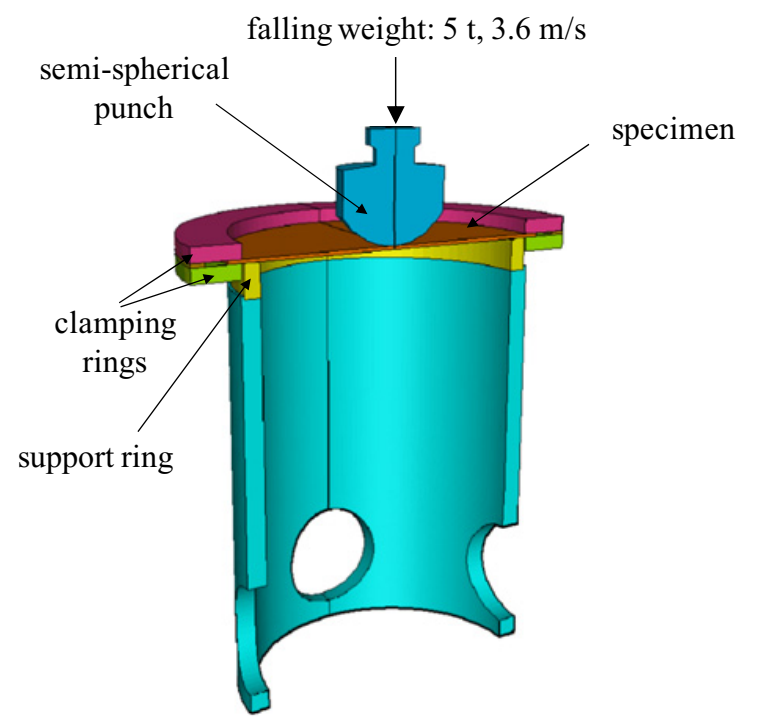

Fig. 3. Details of specimen setup in the impact bulge test.

$5000 \mathrm{~kg}$. The drop weight is precisely guided in the frame with special ball bearings in a four column frame.

The tested plates have the geometry of a disc with a diameter up to $800 \mathrm{~mm}$. The disc is clamped in a ring, which prevents the bending of the material. The testing disc with clamping is put on a bulge cylinder and is impacted by a semi-spherical punch with a radius of $100 \mathrm{~mm}$. Figure 3 shows the details of the test setup. The plate is subjected in this case to a heavy biaxial tensile loading state, followed by a biaxial tensile flow until failure. This is similar to a real dynamic blast loading event. Under blast loading, a biaxial tensile loading state is developed due to the semi rigid frames of the vehicles and the blast wave.

The impact punch is instrumented with four strain gages and calibrated to measure the forces during the test at high test speeds. The deflection is measured using an optical displacement measuring system, which is installed near the test specimen.

In addition, a new testing procedure was developed at Nordmetall $\mathrm{GmbH}$ to measure the dynamic strain field at the lower side of the plate while the punch impacts the upper side with a striking velocity of $3.6 \mathrm{~m} / \mathrm{s}$. This is carried out using the ARAMIS system of the Society for Optical Metrology GOM, Braunschweig. For these high speed tests, two high-speed cameras (PHOTRON SA5) were used to measure $3 \mathrm{D}$-strain fields. The test setup is shown in, figure 4.

With a drop weight of $5000 \mathrm{~kg}$ and a height of more than $1000 \mathrm{~mm}$ (up to $1350 \mathrm{~mm}$, dependent on the test piece configuration and the used punch), the entire impact energy of the Nordmetall-JUMBO-drop weight machine reaches more than $50 \mathrm{~kJ}$. Since the height of the device is $700 \mathrm{~mm}$, a less height is remaining for the free falling height of the drop weight in order to capture a high-speed ARAMIS strain field measurement.

With this facility welded armor plates of steel up to $13 \mathrm{~mm}$ in thickness and of aluminum alloys up to $25 \mathrm{~mm}$ in thickness can be investigated. 


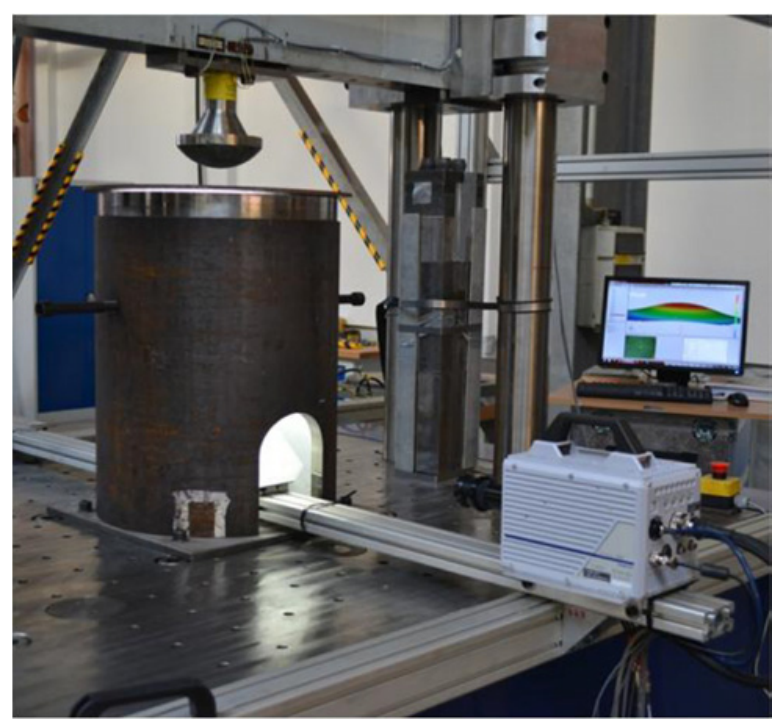

Fig. 4. Camera setup for the impact bulge test.

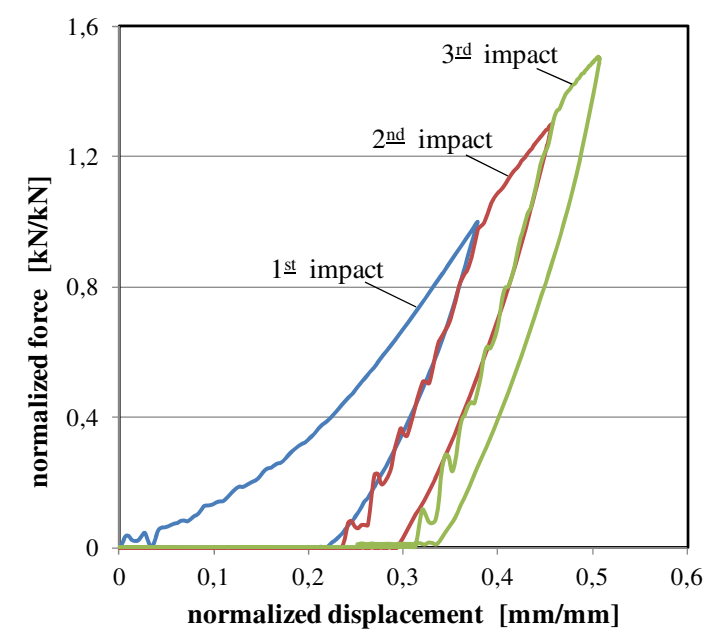

Fig. 5. Force-displacement diagram of tested plain plate.

\section{Results and discussions}

Examples of the normalized measured force-displacement diagrams of plain plates are shown in figure 5. The plate deformed plastically already during the first impact. A dynamic bulge depth of $0.38 \mathrm{~mm} / \mathrm{mm}$ was measured. It rises to $0.46 \mathrm{~mm} / \mathrm{mm}$ by the second impact and $0.51 \mathrm{~mm} / \mathrm{mm}$ by the third impact. The statically measured bulge depth (residual displacement) was $0.22,0.3$ and $0.34 \mathrm{~mm} / \mathrm{mm}$ respectively. The plain plate can withstand an impact energy of more than $30 \mathrm{~kJ}$ without fracture.

To simplify the comparison of all investigated cases, the measured forces are normalized.

Figure 6 shows an example of the measured forcedisplacement diagram of the pre-cracked plates. The crack starts to propagate at a normalized force of nearly 0.39 . At a force of 0.57 secondary cracks are initiated perpendicular to the plane of the pre-crack and are leading to a catastrophic rupture.

Some examples of normalized force-displacement diagrams of the welded plates are shown in figure 7 . From the force-displacement characteristic it can be seen that the

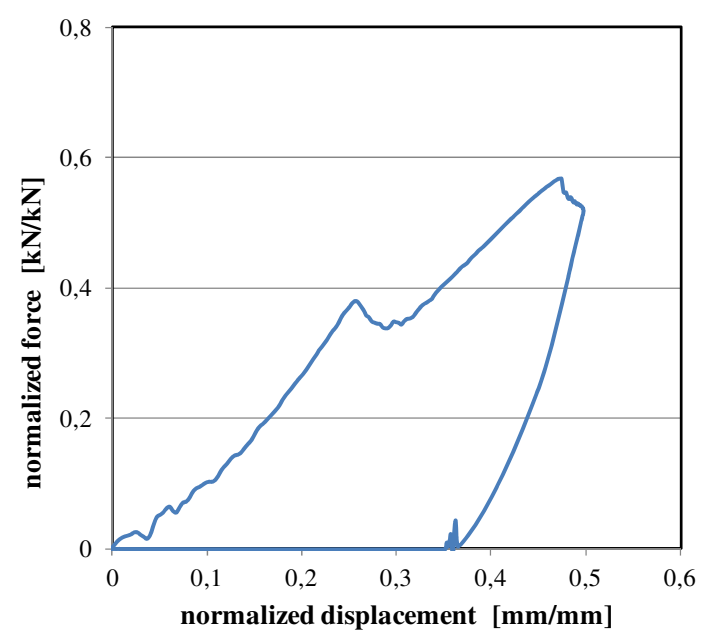

Fig. 6. Force-displacement diagram of pre-cracked plate

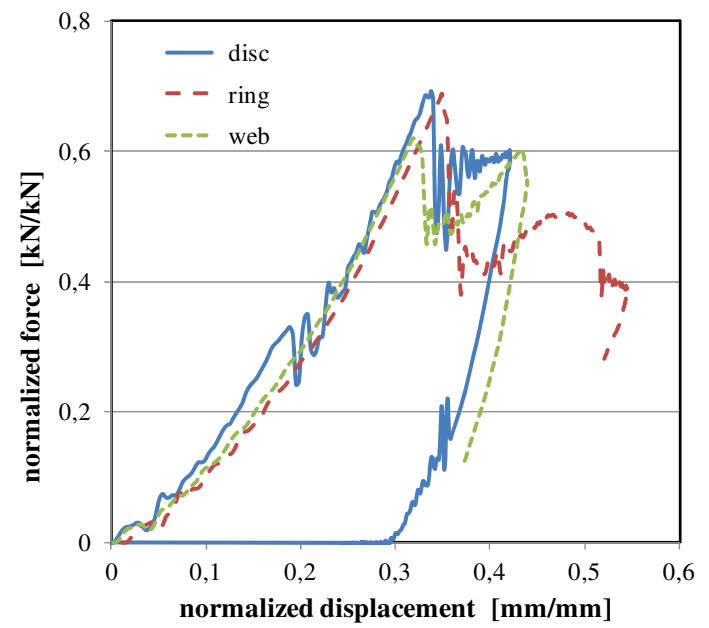

Fig. 7. Force-displacement diagrams of different welded plates.

curve of the welded disc shows a "pop" in at a normalized force of 0.3 . This disc is welded at its outer circumference and represents a second layer under the test plate. Because it is massive, it can not be deformed and causes higher stresses in the weld seam, which leads to the failure. The disc starts to separate from the plate.

In contrary the welded ring and also the weld web are deformable and stay in connection with the plate up to the fracture at the maximum force. The plates of welded discs and welded rings rupture at higher forces than the welded web. That is because that the weld seam is considered as a weak point, at which the fracture initiates. In the plates with the welded web these weak points are at the centre of the plate where the maximum stress and also the maximum strain is located.

Examples of strain fields measured using speckle photography are shown in figure 8 . The deformation of a plain plate starts in the middle and then spreads in the radial direction. It causes only a permanent bulge, figure 8(a). The impact loading is repeated. After three times repeating of impact loading and $3 \times 30 \mathrm{~kJ}$ dissipating energy, the bulge is enlarging but no damage appears. The strain field measured at the pre-cracked plate shows an inhomogeneous strain distribution. As predicted, strain 


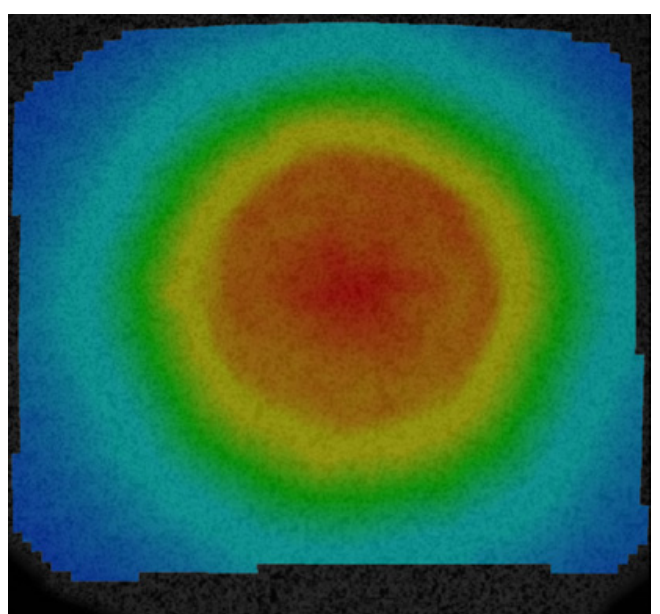

a) plain plate

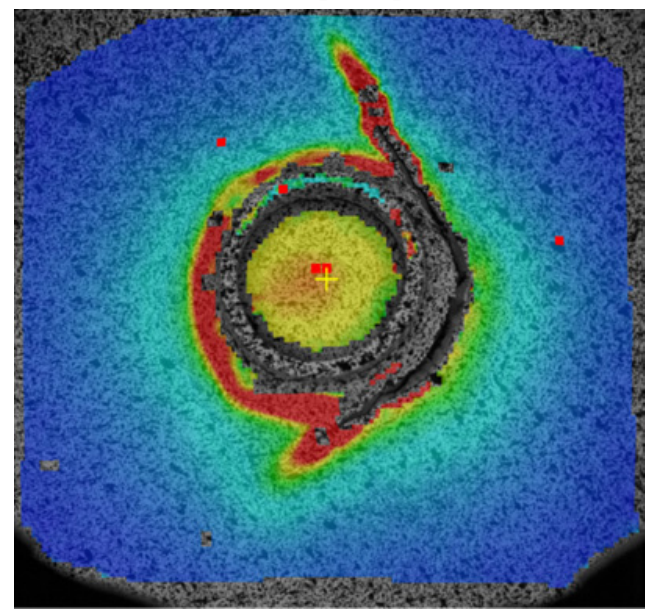

c) plate with welded ring

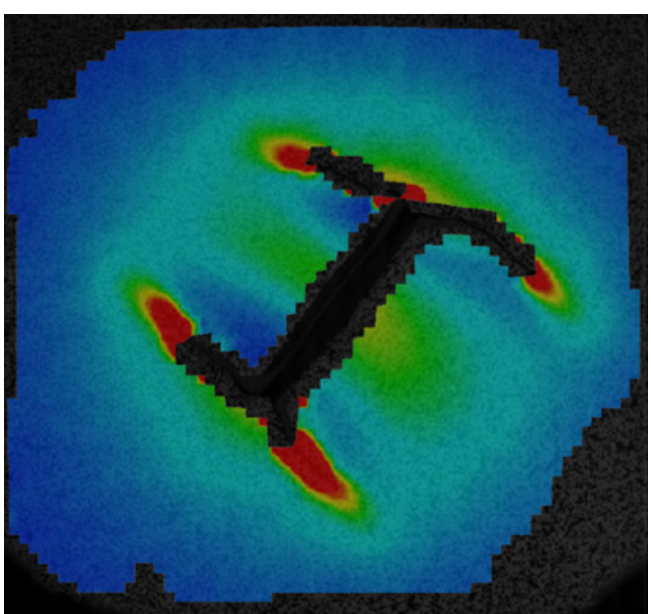

b) pre-craced plate

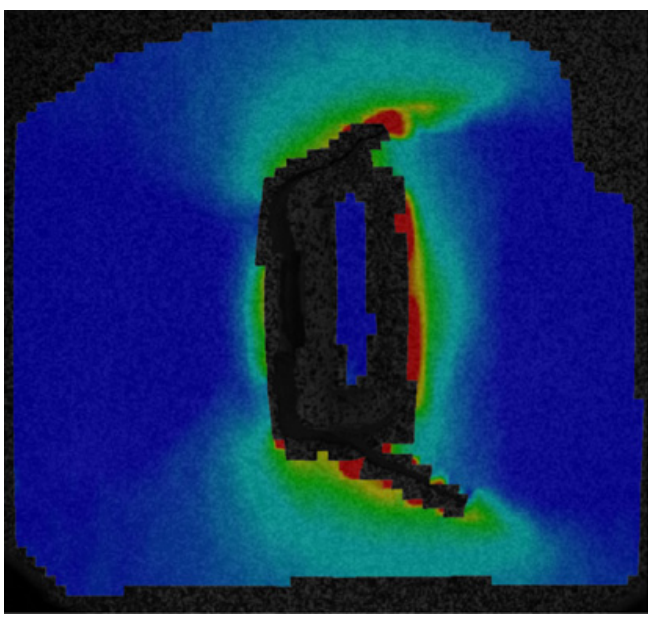

d) plate with welded web

Fig. 8. Strain fields on the lower side of the tested plates measured with speckle photography using high speed cameras $($ red $=$ high strain, blue $=$ low strain).

concentrations are located at the crack tip, figure 8(b). The crack propagates at low forces and leads to the fracture of the plate. A strain field of a plate with a welded ring is shown in figure 8(c). Strain is concentrated in the weld seam and fracture is initiated in the heat affected zone. In the plate with a welded web, figure 8(d), strain concentrations are appearing beside the welding web at the heat affected zone. Fracture occurs later also from this place.

\section{Conclusions}

Experimental simulation of blast loading processes can be realized using an appropriate testing device. The test plate is impacted by a hemispherical punch with nearly $4 \mathrm{~m} / \mathrm{s}$. The local deformation at high strain rates is measured using indirect 3D speckle photography with two high speed cameras.

Dynamic deformability is reduced significantly in plates with an initial crack or welding compared to plain plates.
Cracks initiate at welding or heat affected zone and propagate at relatively low stresses.

\section{References}

1. S. Abdel-Malek, L.W. Meyer, W. Rybakowski, 18.

2. Deutschsprachige ABAQUS Benutzerkonferenz, Erfurt, Germany, 2006, pp. 2.11

3. L.W. Meyer, T. Halle, S. Abdel-Malek, DYMAT 2009, Brussels, Belgium, (2009) 73-79

4. N.K. Gupta, M.A. Iqbal, G.S. Sekhon, Int. J. Impact Engineering, 32 (2006) 1921-1944

5. N.S. Rudrapantna, R. Vaziri, M.D. Olson, Int. J. Impact Engineering, 24 (2000) 457-474

6. S. Chung Kim Yuen, G.N. Nurick, Int. J. Impact Engineering, 31 (2005) 55-83

7. L.W. Meyer, K. Seifert, S. Abdel-Malek, Journal de Physique IV, 1997, C3 571-576

8. L.W. Meyer, S. Abdel-Malek, Journal de Physique IV, 2000, Pr9 63-68 